\title{
A hypothesis regarding the molecular mechanism underlying dietary soy-induced effects on seizure propensity
}

\section{Cara Jean Westmark*}

Department of Neurology, Medical Sciences Center, University of Wisconsin, Madison, WI, USA

\author{
Edited by: \\ Jorge Asconape, Loyola University, \\ USA \\ Reviewed by: \\ Damir Janigro, Cleveland Clinic \\ Foundation, USA \\ Ramkumar Kuruba, Texas A\&M Health \\ Science Center, USA \\ *Correspondence: \\ Cara Jean Westmark, Department of \\ Neurology, Medical Sciences Center, \\ University of Wisconsin, 1300 \\ University Avenue, Madison, WI \\ 53706, USA \\ e-mail:westmark@wisc.edu
}

Numerous neurological disorders including fragile $X$ syndrome, Down syndrome, autism, and Alzheimer's disease are co-morbid with epilepsy. We have observed elevated seizure propensity in mouse models of these disorders dependent on diet. Specifically, soy-based diets exacerbate audiogenic-induced seizures in juvenile mice. We have also found potential associations between the consumption of soy-based infant formula and seizure incidence, epilepsy comorbidity, and autism diagnostic scores in autistic children by retrospective analyses of medical record data. In total, these data suggest that consumption of high levels of soy protein during postnatal development may affect neuronal excitability. Herein, we present our theory regarding the molecular mechanism underlying soy-induced effects on seizure propensity. We hypothesize that soy phytoestrogens interfere with metabotropic glutamate receptor signaling through an estrogen receptor-dependent mechanism, which results in elevated production of key synaptic proteins and decreased seizure threshold.

\section{INTRODUCTION}

Soy was first grown in the United States in the 1760s. This leguminous plant is native to East Asia and related to peas, alfalfa, and clover. Soybeans are the seeds of the soy plant and contain high levels of protein with significant quantities of the essential amino acids. Soybeans are the only plant source of complete protein containing all 20 amino acids. Soybeans are ground to produce soybean oil and soybean meal. Soybean oil is used in food products such cooking oil and in industrial products including plastics and biodiesel fuel. Soybean meal, the protein-rich fraction, is used in food, beverages, and condiments for human consumption as well as in animal feed. According to the American Soybean Association, soybeans were planted on over 75 million acres in the United States in 2012 and were the second largest cash crop with over 3 billion bushels produced. This vegetable protein is used extensively by the food industry in the United States as an additive in nearly all types of foods. Soy protein is also sold as a dietary supplement and is the key ingredient in soy-based infant formulas.

Soy has been purported as a dietary therapy for cardiovascular disease, type 2 diabetes, osteoporosis, hormone-dependent cancers, and the symptoms of menopause, but medical research has been inconclusive in substantiating many of these claims. The FDA recommends that $25 \mathrm{~g} /$ day of soy protein, as part of a diet low in saturated fat and cholesterol, may reduce the risk of heart disease; however, the Nutrition Committee of the American Heart Association reviewed 22 randomized clinical trials comparing isolated soy protein containing isoflavones to milk and other proteins on LDL-cholesterol levels and found the average effect was only $3 \%$ (1). They found no benefit regarding HDL cholesterol, triglycerides, or blood pressure. A subsequent meta-analysis found a $4.2-5.5 \%$ reduction in LDL cholesterol, a $3.2 \%$ increase in HDL cholesterol, and a 10.7\% decrease in fasting triacylglycerol levels suggesting that daily consumption of $15-30 \mathrm{~g}$ of soy significantly improved serum risk factors for cardiovascular disease (2). A meta-analysis of soy product consumption in patients with type 2 diabetes mellitus found that soy protein intake was beneficial in diabetic patients in terms of serum lipids, but there were no significant effects on fasting glucose, insulin, or glycated hemoglobin levels (3). Osteoporosis studies indicate that soy isoflavones stimulate bone formation, inhibit bone resorption, and increase bone mineral density, resulting in attenuation of bone loss in menopausal women (4-9), albeit there are reports of only slight or no clinical effects (10). Cancer meta-analyses indicate that the consumption of soy or soy isoflavones is associated with reduced prostate cancer (11-14), gynecological cancers (15), and possibly breast cancer (16-21). There is no conclusive evidence that soy phytoestrogens reduce hot flashes associated with menopause (22-24). Overall, the literature contains many conflicting reports regarding the health benefits of consuming soy and phytoestrogen supplements. While the FDA has authorized a health claim linking the consumption of soy protein with a reduced risk of coronary heart disease, the agency also lists soy in its poisonous plant database with warnings regarding goiter, growth problems, amino acid deficiencies, mineral malabsorption, endocrine disruption, and carcinogenesis (25).

Perhaps the most controversial use of soy is in soy-based infant formulas. The current position of the American Academy of Pediatrics is, "There is no conclusive evidence from animal, adult human, or infant populations that dietary soy isoflavones may adversely affect human development, reproduction, or endocrine function (26)." And the national toxicology program (NTP) Center for the Evaluation of Risks to Human Reproduction (CERHR) 
found that, "The overall evidence was considered insufficient to reach a conclusion on whether the use of soy infant formula produces or does not produce developmental toxicity with infant exposure in girls or boys at recommended intake levels" (27). In other words, there is not conclusive evidence that soy-based infant formulas are safe. Based on market sales, 12\% of infant formulas in the United States are soy-based (27). Approximately 20-25\% of infants receive some soy-based formula during their first year, but there is no data regarding how many are exclusively fed soybased formula (28). While there may be health benefits for adults associated with the consumption of soy, this natural product holds potential danger for children. Soy products are rich in phytoestrogens, which are natural plant chemicals that have estrogenic and anti-estrogenic properties. The effects of phytoestrogens on fetal and early childhood development have not been extensively studied (29-31). Rodent studies indicate that the placenta acts as a sink for phytoestrogens, and that while transport of phytoestrogens across the placenta is inefficient, low levels are found in the fetus and are sufficient for activation of estrogen receptor beta (ER $\beta$ ) (32). A 4-month-old infant fed soy formula would be exposed to $4.5-8 \mathrm{mg} / \mathrm{kg} /$ day of soy phytoestrogens $(33,34)$, which is $6-11$ times the dose necessary to exert hormone-like effects in adults (33). In placental mammals, the fetus is continuously exposed to high levels of estrogen from the placenta and the mother. Environmental exposure to phytoestrogens during this period is expected to disrupt the function of the natural steroid hormones.

In summary, the safety of long-term soy phytoestrogen consumption remains a controversy. Our research, which is reviewed below, suggests that soy-based diets are associated with increased seizure susceptibility in both rodent and human models of neurological disease. In this Hypothesis and Theory paper for the Diet and Brain Disorders Research Topic of Frontiers in Neurology, we consider the potential molecular mechanism underlying soyassociated effects on seizure propensity. We hypothesize that soy phytoestrogens interfere with metabotropic glutamate receptor (mGluR) signaling through an estrogen receptor (ER)-dependent mechanism, which results in elevated production of key synaptic proteins and decreased seizure threshold in genetically susceptible individuals. First, we summarize our recent research, which implicates soy protein consumption with increased seizure susceptibility. Second, we discuss the potential implications of these findings for infants fed soy-based infant formulas. Third, we review published work in the areas of fragile X syndrome (FXS), mGluR $_{5}$ signaling, and ER signaling that forms the foundation for our hypothesis. Fourth, we present our working model regarding the molecular mechanism underlying soy-induced seizure activity. And finally, we discuss alternative hypotheses that could explain soy-induced health effects.

\section{SOY CONSUMPTION, SEIZURES, AND AUTISM}

Our research has examined audiogenic-induced seizure (AGS) incidence after chronic treatment with $\mathrm{mGluR}_{5}$ antagonists in several transgenic mouse lines $(35,36)$. In pursuit of these objectives, we incorporated the $\mathrm{mGluR}_{5}$ antagonist fenobam into a purified ingredient, soy-free diet that was matched to our standard lab chow (Purina 5015) for protein, fat, and carbohydrate content. We chose to incorporate the drug into a soy-free diet because

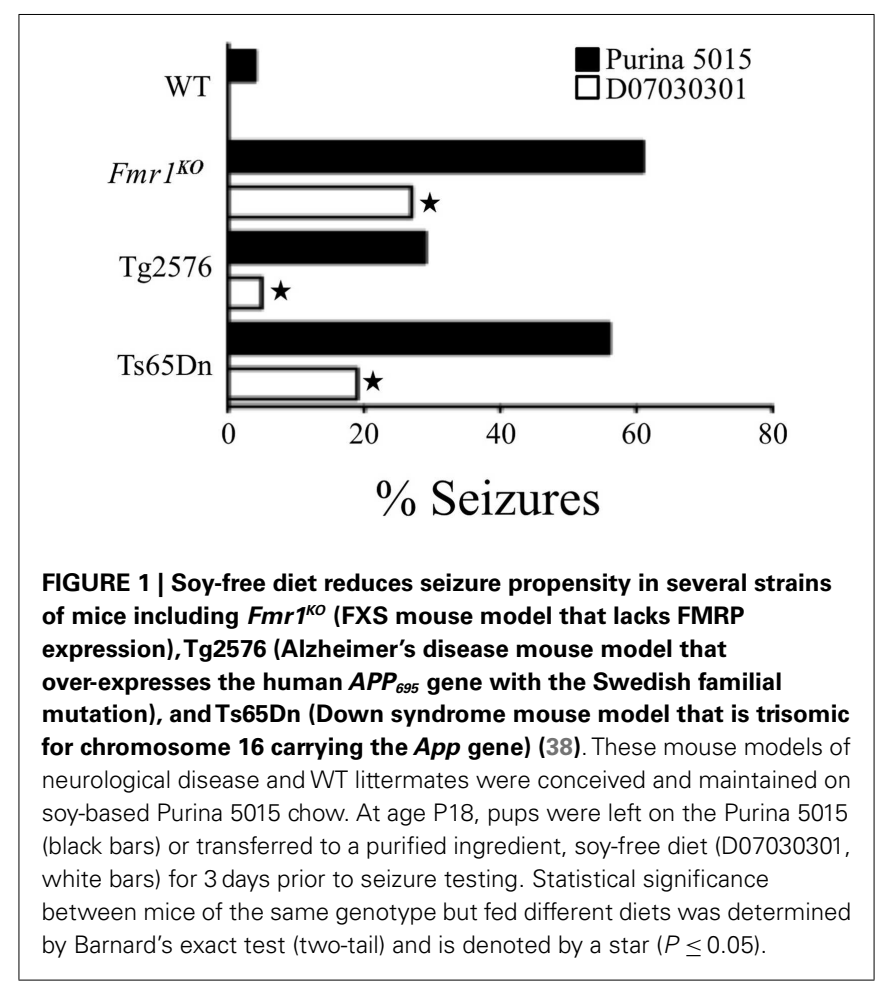

Purina lab chows are grain based and nutrients vary from lot to lot (37). Surprisingly, chronic feeding with the soy-free diet alone (no fenobam added) (D07030301) for 3 days prior to seizure testing drastically attenuated AGS in multiple mouse lines including Fmr1 ${ }^{K O}$ (FXS), Tg2576 (Alzheimer's disease), and Ts65Dn (Down syndrome) (38) (Figure 1). We hypothesized that a longer treatment period might further reduce seizure susceptibility and assessed seizures in Fmrl ${ }^{K O}$ mice conceived and maintained on D07030301 until AGS testing at postnatal day 21. We found a similar AGS rate as the 3-day feeding regimen. Thus, a soy-based diet drastically influences seizure susceptibility in mice.

Purina-type lab chows are grain based with their protein content derived from soybeans (37). Soybeans are rich in phytoestrogens, "plant estrogens," which can be transferred to offspring through the placenta as well as maternal milk. The protein source for the soy-free diet was casein instead of soybean-based, and thus, it did not contain any phytoestrogens. To determine if the AGS phenotype resurfaced in mice conceived on soy-free diet and later exposed to soy, Tg2576 mice born to parents maintained on the soy-free diet were weaned onto Purina 5015 at P18 and tested for seizures at $\mathrm{P} 21$. There was a statistically significant increase in seizures $(36 \%, P \leq 0.05)$ in the Tg2576 fed Purina 5015 for 3 days. We hypothesized that soy phytoestrogens were the seizurepromoting constituent in the Purina 5015. Soy protein is rich in a type of phytoestrogen called isoflavones, which are bioactive compounds structurally similar to the female hormone estrogen. Isoflavones can exert biological activity by mimicking the effects of mammalian estrogens and thus disrupt the endocrine cycle. The three most prevalent isoflavones in soy are genistein, daidzein, and glycitein. Hence, we tested the effects of individual isoflavones on seizures by supplementing the soy-free diet with the 
two most prevalent isoflavones, genistein, or daidzein, at $0.75 \mathrm{~g} / \mathrm{kg}$ feed, which is within the concentration range of isoflavones naturally found in soy products $(39,40)$. Mice were bred on the soy-free diet and at P18 weaned onto daidzein- or genistein-supplemented diets for 3-days prior to AGS testing at P21. Daidzein significantly increased wild running in wild-type mice $(39 \%, P \leq 0.01)$, although 3 days feeding was not sufficient to induce a statistically significant increase in AGS $(21 \%, P \leq 0.1)$. Chronic dosing studies are currently underway. Genistein, or the combination of genistein and daidzein, did not alter wild running, AGS, or death rates suggesting that genistein may counteract the seizure-promoting effect of daidzein and that the ratio of the isoflavones in soy may determine seizure propensity (38).

In addition to our studies, the Hosseini laboratory in Iran has studied the effect of soy extract on pentylenetetrazol (PTZ)induced seizures in rats $(41,42)$. First, they treated rats with repeated low doses of PTZ ( $40 \mathrm{mg} / \mathrm{kg}$ body weight) over 14 days in conjunction with low (20 mg/kg body weight) and high $(60 \mathrm{mg} / \mathrm{kg}$ body weight) doses of soy extract $30 \mathrm{~min}$ before each PTZ injection. Both the low and high doses of soy extract elicited higher seizure scores in ovariectomized (OVX) rats as well as significantly decreased latency times to minimal clonic seizures (MCS) and generalized tonic-clonic seizures (GTCS) (42). Second, they treated male, female, and OVX female rats with high and low doses of soy extract for 14 days followed by injection of a single dose of PTZ ( $90 \mathrm{mg} / \mathrm{kg}$ body weight). They found that the soy extract decreased the latency times to MCS and GTCS in the male and OVX female rats but not in the female rats (41).

A literature search of the terms "soy" and "seizure" produces very few studies. In humans, there are several case reports involving infants with seizure phenotypes in response to consumption of a defective soy formula (Israel study) or who developed micronutrient deficiencies due to soy formula (Canadian study). The Israel study was a follow-up study of seven Israeli, female children, age 5-6 years, with severe epilepsy as a result of thiamine deficiency in infancy caused by a defective soy-based formula (43). Their findings indicated that severe infantile thiamine deficiency might result in epilepsy. The seizures were refractory to most antiepileptic drugs with four children having uncontrolled seizures and all children exhibiting mental retardation and brainstem dysfunction. The Canadian study reported on three case articles of infants presenting with hypocalcemic seizures during the winter months while being fed soy formula (44). The study population included three infants with different ethnic backgrounds and living in different geographical regions of Eastern Canada. All of the subjects were male and 6 week- to 2-months old and presented with hypocalcemic seizures attributable to vitamin D deficiency. Laboratory results were consistent with vitamin $\mathrm{D}$ deficiency despite receiving daily recommended intake levels.

There have been studies examining cognitive and reproductive development in infants fed soy-based infant formula. Malloy and Berendes tested 9- to 10-year-old-children who had been fed soy-based infant formula or human milk during their first year of life and found no difference in IQ, behavioral problems, learning impairment, or emotional problems (45). A study by Strom and colleagues surveyed adults age 20-34 years old who had participated as infants in controlled feeding studies between
1965 and 1978 (46). The study population included 811 subjects including males $(n=120)$ and females $(n=128)$ who had been fed soy-based infant formula. The outcomes were that no correlation was found between infant formula use and education level, but women in the soy cohort reported longer duration of menstrual bleeding (about $8 \mathrm{~h}$ ) and greater discomfort with menstruation. The soy cohorts also had a higher reported use of asthma or allergy drugs and greater tendency toward sedentary activities. The consumption of soy-based infant formula has also been associated with breast development (47) and premature thelarche (48).

There have been several rodent studies assessing the effect of soy phytoestrogens on seizures, which are described above. The problem with studying soy in rodents is that they metabolize soy isoflavones differently from humans. Thus, the data may not be generalizable between species. It should be noted that infants can efficiently digest, absorb, and excrete genistein and daidzein from soy-based infant formulas (49). Urine was collected from disposable diapers (3-5 diapers worn during a 24 -h period) of infants (4 received soy-based formula and 25 received cow milk-based formula). Isoflavones were extracted from the diapers every 12 weeks from a starting age of 2-6 weeks and continuing until 16 weeks of age and detected by HPLC. Isoflavone (genistein plus daidzein) levels remained constant at $3.2 \pm 0.2 \mathrm{mg} / \mathrm{kg}$ body weight regardless of age. Rodents conjugate isoflavones less efficiently and thus have higher circulating concentrations of biologically active forms (50). With this caveat noted, studies in rats and mice have demonstrated that soy increases seizure propensity. In addition to the aforementioned rodent studies, the effects of soy have been studied in monkeys and in vitro. Dietary soy is associated with epigenetic changes in monkeys such that overall methylation in liver and muscle tissue was increased when switching from a soy-based to casein-based diet (51). At high doses, genistein and daidzein are toxic to primary neuronal cultures (52).

Overall, a soy-based diet significantly increases seizure propensity in genetically susceptible mice and daidzein is likely a contributing factor. The amount of daidzein consumed per body weight per day by juvenile mice is comparable to the daily isoflavone intake of infants fed soy-based formula $(34,53)$ suggesting that these findings could have important clinical relevance.

Hence, we conducted a retrospective analysis of seizure incidence in autistic children fed soy- versus casein-based infant formula. Seizures are a prevalent phenotype in autism (21-38\%) $(54,55)$. We utilized medical record data from the Simons Foundation Autism Research Initiative - Simons Simplex collection (SFARI-SSC) to assess seizure incidence in autistic children fed soy-based versus other infant formula. There were data available for 1949 subjects ( $87 \%$ males). We found a 2.6-fold increase in the incidence of febrile seizures and a 4.8 -fold increase in the incidence of simple partial seizures in autistic children fed soy formula (56) (Table 1). The soy-based formula was not associated with statistically higher rates of infantile spasms, atonic (drop attack), grand mal (generalized tonic clonic), petit mal (absence), or complex partial seizures. There was a 2.1-fold increased incidence of epilepsy. In aggregate, these data demonstrate that a soy-based diet is associated with increased seizure incidence in both mouse models of neurological disease and in autistic children. These data 
Table 1 | Prevalence of seizures in autism subjects dependent on soy formula.

\begin{tabular}{lll}
\hline Phenotype & Soy & Non-soy \\
\hline Febrile seizures (\%) & $4.2^{* *+\dagger}$ & 1.6 \\
Infantile spasms (\%) & 0.60 & 0.063 \\
Atonic seizures (\%) & 0.30 & 0.13 \\
Grand mal seizures (\%) & 1.2 & 1.9 \\
Petit mal seizures (\%) & 3.3 & 2.0 \\
Simple partial seizures (\%) & $1.2^{\dagger}$ & 0.25 \\
Complex partial seizures (\%) & 0.60 & 0.38 \\
Epilepsy diagnosis (\%) & $3.6^{* \dagger}$ & 1.7 \\
\hline
\end{tabular}

Minimum number of subjects per cohort $=330$ (soy) and 1563 (non-soy).

${ }^{*} P \leq 0.05$ and ${ }^{*} P \leq 0.01$ as determined by the Pearson's uncorrected chi-squared test.

${ }^{\dagger} P \leq 0.05$ and ${ }^{t+} P \leq 0.01$ as determined by Fisher's exact test (two-tail).

raise important questions regarding the neurological side effects of a soy-based diet during postnatal development.

We also assessed developmental milestones and autism testing scores in the SFARI autism population dependent on soy-based infant formula. There were no statistically significant differences in developmental milestones (age first walked, age of first single word, or age of first phrase) dependent on soy or non-soybased infant formula use. We did find exploratory associations between the consumption of soy-based infant formula and several autistic behaviors as assessed by sub-score and line-item analysis of the aberrant behavior checklist $(\mathrm{ABC})$, autism diagnostic interview-revised (ADI-R), and autism diagnostic observation schedule (ADOS) (57). It is important to note that these findings were exploratory in nature as the SFARI data collection protocol was neither specifically designed to assess the effects of infant formula on autistic behaviors nor powered to detect multiple hypotheses based on line-item analyses of diagnostic tests.

There are limitations to the retrospective human data described above including declarative data regarding the epilepsy diagnoses, lack of data regarding potentially confounding issues, and less female subjects than male. A diagnosis of epilepsy was defined as either a specific report of epilepsy on the ADI-R or at least two seizures on the medical record history report, which are based on parental recall. A neurologist did not verify the diagnoses; however, NINDS considers detailed medical history reports of seizure history one of the best methods available to identify if a person has epilepsy as well as the type of seizures. Recall bias regarding infant formula usage is not an expected problem as parents typically switch formulas for very specific reasons such as gastrointestinal problems or allergies. There are confounding issues associated with the consumption of soy-based infant formula that will need to be addressed in future, prospective studies such as the reasons the infants were fed soy-based formula and the duration of feeding with the soy-based formula. It is possible that soy is a surrogate marker for an underlying condition that lowers seizure threshold. For example, infants that are fed soy-based infant formula due to cow milk protein allergies could be more vulnerable to illnesses associated with fever-induced convulsions. We can not make a definitive conclusion regarding this scenario based on retrospective data; however, in the SFARI study population utilized for our analysis, no subjects reported both allergies and febrile seizures. In accordance with current autism prevalence rates, there were significantly less female subjects than males in the study. Despite the lower number of females, the use of soy-based infant formula was associated with febrile seizures in females. A larger female cohort is required to confirm whether the use of soy-based infant formula is associated with epilepsy comorbidity in autistic girls.

\section{IMPLICATIONS OF SOY-BASED INFANT FORMULAS ON CHILDHOOD NEUROLOGICAL DEVELOPMENT}

The presented data suggest that the consumption of soy-based diets is associated with reduced seizure threshold in several mouse models of neurological disease as well as in a vulnerable population of children diagnosed with autism. These results require prospective evaluation regarding the effects of soy on childhood development particularly in infants genetically predisposed to seizure disorders. Many developmental disabilities are co-morbid with seizures and epilepsy including FXS, autism, and attention deficit/hyperactivity disorder (ADHD).

Fragile $\mathrm{X}$ syndrome is the most common form of inherited mental retardation and the leading known genetic cause of autism. This X chromosome-linked disorder is clinically characterized by highly variable intellectual disability (overall IQ $<70$ ), autisticlike behavior, seizures, macrocephaly, and macroorchidism (58). FXS results from a mutation in a single gene on the X chromosome, FMR1. In the majority of cases, a $>200$ copy trinucleotide (CGG) repeat expansion in the $5^{\prime}$-UTR of the FMR1 gene (59) is associated with transcriptional silencing of the FMR1 promoter and loss of expression of fragile $\mathrm{X}$ mental retardation protein (FMRP) (60). FMRP is a multi-functional mRNA binding protein that is involved in the transport, localization, and translational regulation of mRNA ligands and is required for normal dendrite development. FMRP expression is absent or greatly reduced in FXS and many FXS phenotypes are manifested in $F m r 1^{K O}$ mice, which lack expression of FMRP. In the preceding section, we demonstrated an increased incidence of AGS in a mouse model of FXS in response to a soy-based diet. FXS is a family of disorders also including the FMR1 premutation disorders fragile $\mathrm{X}$-associated primary ovarian insufficiency (FXPOI) and fragile X-associated tremor/ataxia syndrome (FXTAS). There is an increased prevalence of seizures in boys with the FMR1 premutation co-morbid with autism spectrum disorders (ASD) (61).

Autism is a cluster of complex neurobiological disorders that normally present in the second or third years of life. The core features include impairments in social interaction and communication and repetitive stereotyped behavior. Many autistic children are mentally retarded and half exhibit marked delay in motor milestones. ASD are estimated to occur in 1 in 88 children with prevalence 4.7 -fold higher in males (62). The etiology of autism is not known but genetic as well as environmental factors likely affect the severity of symptoms (63-65). For example, autism is highly co-morbid with other developmental disorders such as FXS where $67 \%$ of males and $23 \%$ of females meet the diagnostic criteria for ASD (66). Epilepsy is highly co-morbid in autism with a prevalence of $21.4 \%$ in autistic subjects with intellectual disability and $8 \%$ in 
subjects without intellectual disability (67). EEG abnormalities were found in $31 \%$ of children with ASD (68), and are associated with language disorders (69). It has been proposed that epilepsy drives autism in neurodevelopmental disorders (70, 71).

Attention deficit/hyperactivity disorder is the most common neurobehavioral disorder diagnosed in children with a worldwide prevalence of 5.3\% (72) and a national prevalence of 9.0\% (73). ADHD is characterized by in attention, impulsivity, and hyperactivity. The diagnostic and statistical manual of mental disordersfourth edition (DSM-IV) diagnosis requires the presence of six out of nine specific behavioral and functional symptoms of inattention or hyperactivity/impulsivity for a duration of at least 6 months, with onset before age 7 years. ADHD is highly co-morbid with ASD and epilepsy. Up to $70 \%$ of ASD cases (74) and $38 \%$ of children with epilepsy exhibit ADHD (75-77). ADHD is significantly more common among children with newly diagnosed epilepsy than among controls suggesting that there is a common antecedent for both conditions $(78,79)$.

Several factors could contribute to the comorbidity of epilepsy with these developmental disorders, such as underlying brain pathology, genetic susceptibility genes, and/or environmental and dietary factors that exacerbate epileptiform activity. It is estimated that there are over 350 autism susceptibility genes (80). Dietary factors remain less well characterized. The prevalence of epilepsy in patients with celiac disease is $5.5 \%$ (81). Elevated levels of manganese are associated with neurocognitive deficits $(82,83)$, and it has been proposed that soy-based infant formula may cause ADHD due elevated manganese content (84). We hypothesize that soy phytoestrogens are a dietary factor that increases epileptiform activity, which leads to the development of ADHD and autism. In Israel where there is widespread use of soy-based formula without clinical indications ( $70 \%$ of children receive soy for $>6$ months) (85), there is a high rate of ADHD (12.6\%) (86). In the SFARI autism population described in the previous section, we observe a statistically significant increase in ADHD with the consumption of soy-based infant formula (6.7\% soy, 3.9\% non-soy, 1.7 -fold increase, $P=0.04$ ). Thus, the consumption of soy-based infant formulas may be altering neuronal excitability and contributing to the increased incidence and/or severity of neurological disorders.

\section{FXS AND mGIuR SIGNALING}

Seminal work by Drs. Kim Huber and Mark Bear has shown that excessive signaling through $\mathrm{mGluR}_{5}$ contributes to many of the psychiatric and neurological aspects of FXS (87). Genetic reduction of $\mathrm{mGluR}_{5}$ in an $\mathrm{Fmrl}^{\mathrm{KO}}$ background (88) or pharmacological treatment with an $\mathrm{mGluR}_{5}$ inhibitor (89-91) rescues many FXS and autistic phenotypes. mGluRs belong to the G-protein-coupled receptor superfamily. There are eight identified subtypes of mGluR that have been classified into groups based on sequence homology and signaling properties. Group $1\left(\mathrm{mGluR}_{1}\right.$ and $\left.\mathrm{mGluR}_{5}\right)$ are generally postsynaptic in location, couple to $\mathrm{G}_{\mathrm{q}}$, and activate phospholipase C. $\mathrm{mGluR}_{5}$, which signals through FMRP, has been the major target of drug discovery for FXS over the past decade (87). The "mGluR theory of FXS" proposes that FMRP binds to synaptic mRNAs and represses their translation. Upon mGluR $_{5}$ activation, FMRP is dislodged or inactivated, and translation proceeds. This accounts for "regulated translation" at the synapse. In the absence of FMRP, as in FXS, mGluR $_{5}$-mediated translation is constitutive and unregulated. Over the past two decades, there have been pivotal advances regarding the identification of downstream signaling molecules and translational targets in the $\mathrm{mGluR}_{5} / \mathrm{FMRP}$ pathway by academia as well as the development of numerous robust mGluR $_{5}$ inhibitors by pharmaceutical companies. However, there is a paucity of knowledge regarding the upstream activators and environmental factors that stimulate $\mathrm{mGluR}_{5}$ signaling. Based on our preliminary data presented above, we hypothesize that estrogenic compounds in soy stimulate $\mathrm{mGluR}_{5}$ signaling and thus contribute to FXS pathogenesis.

\section{ER SIGNALING AT THE SYNAPSE}

The major "female" and "male" steroid hormones are classified as estrogens and androgens, respectively. Both classes of hormones are found in both genders but in different quantities. The most predominant and potent estrogen is estradiol. Estradiol can be synthesized by the endocrine glands and secreted into the bloodstream and thereby enter and stimulate target tissues including the brain. Estradiol can also be synthesized locally within the brain (92) de novo from cholesterol or derived from testosterone by P-450 aromatase, also known as estradiol synthase, through an aromatization reaction. Hippocampal neurons produce P-450 aromatase and generate estradiol (93). Estradiol acts on both the alpha and beta forms of ER, ER $\alpha$ and ER $\beta$, which are primarily localized in the cell nucleus where they act as ligand-regulated transcription factors by binding to specific estrogen response elements (ERE) on DNA, i.e., "classical ER signaling." However, accumulating evidence demonstrates that ER $\alpha$ and $\operatorname{ER} \beta$ are also found at cell membranes where they interact with mGluRs to initiate cell signaling, i.e., "non-classical ER signaling." The Mermelstein laboratory has proposed the "ER/mGluR hypothesis" to explain the rapid membrane actions of estrogen in the nervous system. Their theory purports that direct proteinprotein interactions between ER and mGluRs allow estradiol to signal through mGluRs. Upon estradiol binding to the ER, the ER alters the conformation of mGluR, resulting in activation of the downstream G-proteins and second messenger signaling without the requirement for glutamate (94). Both ER $\alpha$ and ER $\beta$ are detected on dendritic spines and axon terminals; however, ER $\beta$ has more widespread localization to extranuclear sites suggesting that this isoform may be more important in mediating rapid estrogen signaling at membranes (95).

Soy phytoestrogens can act as endocrine disrupting chemicals (EDC) (96), and the developing fetus and neonate are particularly vulnerable to their effects. EDC bind to ER and induce ER-mediated gene expression and altered cell signaling. Periand postnatal exposure to EDC are expected to disrupt the hypothalamic-pituitary-gonadal axis (HPG axis), which is critical for the development of the reproductive and immune systems. It has been hypothesized that premature activation of the HPG axis is the cause of growth impairment in FXS (97). Thus, dietary exposure to high levels of soy phytoestrogens during infancy could negatively impact growth and development.

There is a paucity of studies regarding the effects of phytoestrogens on neuronal excitability. It is known that genistein is a broad-spectrum tyrosine kinase inhibitor, and tyrosine kinases 
modulate synaptic plasticity and ion channel function. Genistein has been shown to decrease neuron excitability in Aplysia sensory neurons (98), 3,5-DHPG-induced membrane potential oscillations in striatal cholinergic interneurons (99), and excitability of capsaicin-sensitive neurons from cultured rat trigeminal ganglion neurons (100). Daidzein, which is a structural analog of genistein, that does not possess protein tyrosine kinase inhibitor activity, also decreases excitability but to a lesser extent than genistein (100). Much remains to be learned regarding the effects of daidzein and other phytoestrogens on neuronal excitability.

\section{MELDING THE BEAR “mGIUR THEORY OF FXS" WITH THE MERMELSTEIN “ER/mGIUR HYPOTHESIS"}

An important, unanswered question regards how soy and/or soy isoflavones affect neuron function. Both genistein and daidzein inhibit $\mathrm{GABA}_{\mathrm{A}} \mathrm{R}$ (101), which is the major inhibitory receptor in the brain with roles in seizures, hyperactivity, learning and memory, and sleep/wake cycles. Alternatively, or perhaps concurrently, soy isoflavones could affect neuronal function through $\mathrm{mGluR}_{5}$ signaling. We are exploring the hypothesis that soy phytoestrogens such as daidzein promote altered $\mathrm{mGluR}_{5} / \mathrm{ER} / \mathrm{scaffolding}$ protein interactions, resulting in activated $\mathrm{mGluR}_{5}$ signaling, which leads to increased epileptiform activity. This hypothesis developed from our data described above demonstrating that dietary soy consumption is associated with increased seizure incidence in $\mathrm{Fmrl}^{\mathrm{KO}}$ mice (38) and in autistic children (56). These data in conjunction with published reports demonstrating the interaction between ER and mGluRs (102-105) suggest that soy phytoestrogens could exacerbate $\mathrm{mGluR}_{5}$ signaling through an ER-dependent mechanism. Excessive levels of estrogenic compounds are predicted to increase $\mathrm{mGluR}_{5}$ activation and downstream signaling, particularly in FXS where the FMRP translational brake is absent. Thus, we propose that coupling the Bear "mGluR theory of FXS" with the Mermelstein "ER/mGluR hypothesis" provides a plausible mechanism through which estrogenic compounds such as soy phytoestrogens lower seizure threshold (Figure 2).

\section{ALTERNATIVE HYPOTHESES}

There are alternative hypotheses, which could explain how soy lowers seizure threshold including non-neuronal targets. For example, understanding how the bacteria in the gut can affect the brain and disease development is an emerging area of important research. Bacteria in the gut have the potential to communicate with the brain through the vagus nerve, by modulating the immune system and/or by synthesizing novel neurotransmitters. It is known that soy isoflavones affect the development of the intestines as well as the make-up of the intestinal microbiota (106). There have been two studies investigating the influence of soy-based infant formula on the gut microflora in infants and/or children. The first study found increased equol excretion in the soy group (19\%) compared to controls (5\%) with elevated Bifidobacteria, Bacteroides, and Clostridia bacteria in fecal samples from the soy group (107). The second study found elevated Bifidobacteria species (B. adolescentis and B. infantis), which were not detected before commencing the soy-based formula (108). Bifidobaterium, Bacteriodes, and Clostridium are among the human intestinal bacteria that can produce $S$-equol $(109,110)$, which is the biologically active metabolite

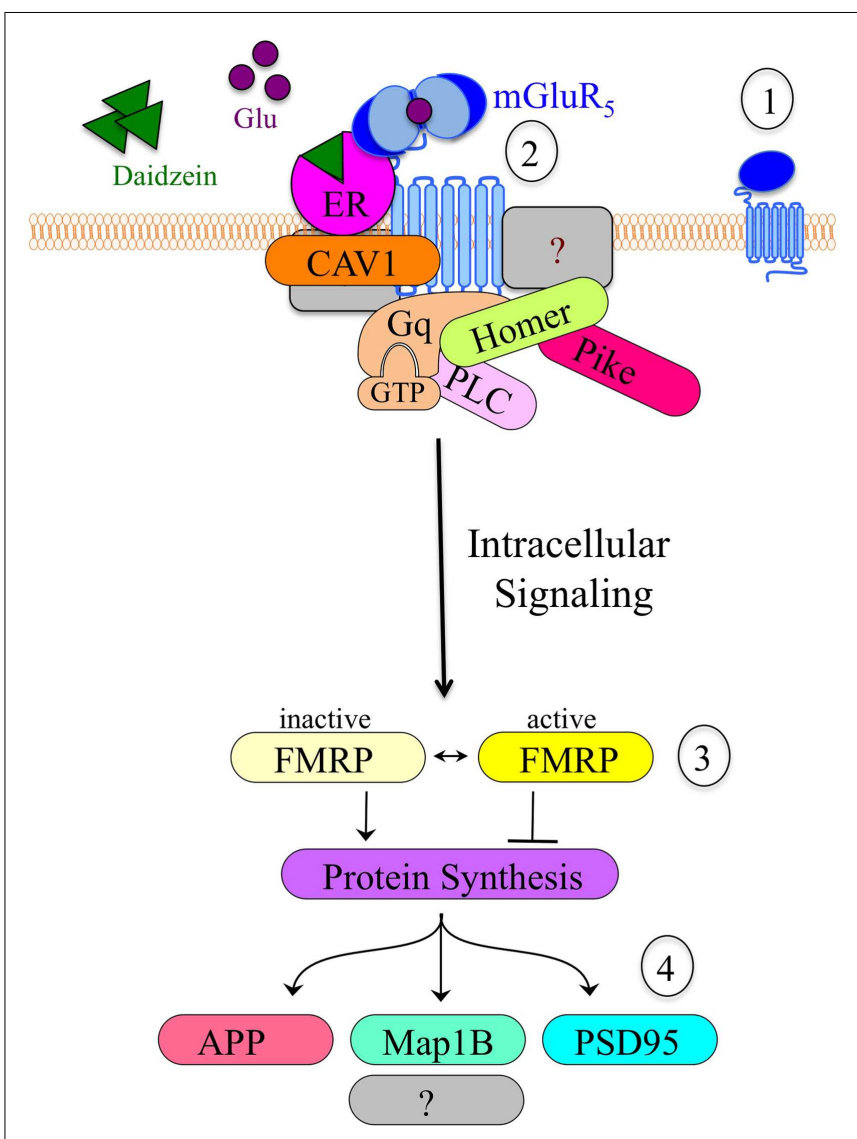

FIGURE 2 | Model of the hypothetical estrogen-induced signaling pathway in neurons. (1) $\mathrm{mGluR}_{5}$ is a primary target for drug development in FXS. (2) Cell stimulation causes clustering of $\mathrm{mGluR}_{5}$ receptors and altered interactions with scaffolding proteins such as ER, caveolin and Homer, which likely alter downstream signaling events. Daidzein or other estrogenic compounds act as ER agonists. (3) $\mathrm{mGluR}_{5}$ is known to signal through FMRP, a translational repressor. The absence of FMRP in Fmr ${ }^{K O}$ cells results in constitutive, unregulated protein synthesis in response to $\mathrm{mGluR}_{5}$ stimulation. (4) Altered $\mathrm{mGluR}_{5} /$ FMRP signaling modulates the synthesis of numerous synaptic proteins including APP,

microtubule-associated protein 1B (Map1B), and postsynaptic density protein 95 (PSD95). Excessive production and accumulation of these synaptic proteins contributes to elevated epileptiform activity and FXS pathology.

of daidzein. Intestinal bacteria transform daidzein to equol in humans that are equol producers. In Japan, Korea, and China, up to $80 \%$ of people are equol producers, but as few as $25 \%$ of people in North America and Europe can biotransform daidzein into equol (110). Equol modulates expression of the BRCA1 and BRCA2 breast cancer genes through an epigenetic mechanism, resulting in decreased methylation (111). The effect of equol on the methylation of neuronal genes has not been studied.

DNA and protein constituents of soy may also affect brain function. It was long thought that large macromolecules do not pass directly from the digestive tract to the circulatory system. Emerging evidence is proving this paradigm false. Meal-derived DNA fragments that are large enough to carry intact genes can avoid degradation by the stomach acid, enter the human circulatory 
system, and be detected in blood plasma (112). In addition to plant DNA, $>90 \%$ of soybeans are genetically modified (GM) and carry bacterial genes that can code for toxic proteins. It has been estimated that if there were a 1 in a billion event of bacterial transformation of GM DNA into gut bacterium and that with 1E15 bacteria in the human gut, one would potentially have 1 million transformed bacteria in the intestines (113). These transformed bacteria could constitutively express toxic proteins that could damage the intestinal lining and cause disorders like celiac disease in which peptides enter the circulatory system, stimulate antibody production, and lead to autoimmune reactions that can affect neurological function. The second most common GM trait codes for a built-in pesticide produced by the soil bacterium Bacillus thuringiensis $(\mathrm{Bt})$.

Besides the macromolecular content of food (DNA and protein), chemical contaminants associated with soy have strong potential to affect neurological and gut function. There is a strong correlation between glyphosate usage and modern disease incidence (114). Moms Across America and Sustainable Pulse conducted a small study of lactating mothers across the United States. They found high levels of glyphosate $(76-166 \mathrm{mg} / \mathrm{L})$ in 3 out of 10 breast milk samples. Glyphosate is sprayed on GM crops where it acts as both a pesticide and herbicide, as well as on other crops where it serves as a drying agent. This chemical that accumulates in the soil is not easily degraded and is a known antibiotic and endocrine disruptor. The Moms Across America was a small, grassroots study to encourage future, controlled, scientific investigation in this area. They could not afford to do a sensitive HPLC analysis; thus, the prevalence of lactating mothers with glyphosate in their breast milk could be higher than reported. There is one anecdotal report of the negative detection of glyphosate coinciding with the disappearance of inflammation and autism symptoms in an 8-year-old boy after 6 weeks on an organic diet and 2 weeks of reverse osmosis filtered water that tested negative for glyphosate.

Finally, substantial evidence suggests that activation of the immune system is associated with epilepsy $(115,116)$, and consumption of soy and soy phytoestrogens is associated with activation of the immune system. Specifically, soy-based diets alter cytokine production through an ER $\alpha$-dependent pathway (117). Mice fed high doses of daidzein (20 and $40 \mathrm{mg} / \mathrm{kg} /$ day) for 7 consecutive days exhibit enhanced non-specific immunity, humoral immunity, and cell-mediated immunity (118). In addition, exposure to environmental estrogenic compounds is implicated in the increased prevalence of autoimmune disorders (119). Thus, soy phytoestrogens and/or estrogenic pesticides associated with soy may indirectly affect seizure propensity through modulation of the immune system. This alternative hypothesis may occur through disruption of the blood-brain barrier (BBB). Recent work from Bargerstock and colleagues has shown that peripheral immunity may regulate changes in the $\mathrm{BBB}$ through a $\mathrm{BBB}$ integrity biomarker, $\mathrm{S} 100 \mathrm{~B}$, which is detected in blood when the $\mathrm{BBB}$ is compromised. Pilocarpine-induced status epilepticus is also associated with increased circulating levels of S100B, which is thought to trigger an autoimmune reaction (120). The original finding that prompted the development of this hypothesis paper was an association between febrile seizure incidence and the consumption of soy-based infant formula (56). Fevers increase brain temperature in part through the release of inflammatory cytokines, which are likely involved in the generation of febrile seizures (121). Thus, interactions between the immune and nervous systems via a compromised BBB may affect seizure propensity with dietary factors such as soy acting as an immune system trigger.

\section{CONCLUDING REMARKS}

In summary, soy infant formula has been used in the United States since 1909 as an alternative for infants allergic to cow's milk. Published estimates of formula intolerance range from 2 to $7.5 \%$; yet, about a quarter of infants are fed soy-based formulas suggesting that non-standard, soy-based formulas are used excessively (122). Understanding the health consequences of soy phytoestrogens and modulating intake of these compounds during pregnancy and infancy could potentially decrease the development and/or exacerbation of childhood neurological disorders. There have been no clinical trials examining the effects of soy-based formulas on seizures or neurological development in infants with developmental disabilities. These vulnerable groups may be more susceptible to seizure-promoting ingredients in the diet. Prospective studies are required to validate the rodent and human analyses described herein. There are numerous potentially confounding factors that need to be addressed, most notably, the lack of data regarding the age of initiation and the duration of feeding with soy-based infant formula. Studies examining the health effects of soy and soy phytoestrogens are further complicated by the fact that Monsanto marketed GM soy in 1995. Glyphosate-tolerant soybeans were genetically engineered to express the 5-enolpyruvyl shikimic acid-3-phosphate (EPSP) synthase gene from Agrobacterium sp. (strain CP4), which infers resistance to Roundup ${ }^{\circledR}$ herbicide. Currently, 93\% of the soybean crops in the United States are GM. Glyphosate, the active ingredient in Roundup ${ }^{\circledR}$, is a major environmental toxin implicated in the increased incidence of autism, Alzheimer's disease, cancer, and many other diseases (114). Thus, considering the lack of existing data regarding the long-term neurological consequences of consuming a soy-based diet during infancy, particularly in children with developmental disabilities, alternative formulas should be considered when clinically indicated.

\section{HUMAN SUBJECTS}

All studies conducted by the author in rodents or by retrospective analyses of human medical record data were performed in accordance with institutional and national guidelines and regulations. The mouse studies were conducted under an approved University of Wisconsin-Madison animal care protocol administered through their Animal Resource Center. The institutional review protocol governing the Simons Simplex collection was approved by the Institutional Review Board at Columbia University Medical Center. Written informed consent was provided by all guardians or research subjects. The privacy of participants was protected by using global unique identifiers. The research protocol for using the Simons Simplex collection in the studies described herein was approved by the Human Research Protection Program at the University of Wisconsin-Madison, which determined that the study qualified for exemption. 


\section{ACKNOWLEDGMENTS}

The described studies were supported by funding from NICHD (HD075881), NCATS (9U54TR000021), and FRAXA Research Foundation. The author thanks Dr. Pamela Westmark for critical review of the manuscript.

\section{REFERENCES}

1. Sacks FM, Lichtenstein A, Van Horn L, Harris W, Kris-Etherton P, Winston M. Soy protein, isoflavones, and cardiovascular health: a summary of a statement for professionals from the American heart association nutrition committee. Arterioscler Thromb Vasc Biol (2006) 26(8):1689-92. doi:10.1161/01.ATV. 0000227471.00284.ef

2. Anderson JW, Bush HM. Soy protein effects on serum lipoproteins: a quality assessment and meta-analysis of randomized, controlled studies. J Am Coll Nutr (2011) 30(2):79-91. doi:10.1080/07315724.2011.10719947

3. Yang B, Chen Y, Xu T, Yu Y, Huang T, Hu X, et al. Systematic review and metaanalysis of soy products consumption in patients with type 2 diabetes mellitus. Asia Pac J Clin Nutr (2011) 20(4):593-602.

4. Ma D, Qin L, Liu B, Wang P. Inhibition of soy isoflavone intake on bone loss in menopausal women: evaluated by meta-analysis of randomized controlled trials. Wei Sheng Yan Jiu (2009) 38(5):546-51.

5. Ma DF, Qin LQ, Wang PY, Katoh R. Soy isoflavone intake increases bone mineral density in the spine of menopausal women: meta-analysis of randomized controlled trials. Clin Nutr (2008) 27(1):57-64. doi:10.1016/j.clnu.2007.10.012

6. Ma DF, Qin LQ, Wang PY, Katoh R. Soy isoflavone intake inhibits bone resorption and stimulates bone formation in menopausal women: metaanalysis of randomized controlled trials. Eur J Clin Nutr (2008) 62(2):155-61. doi:10.1038/sj.ejcn.1602748

7. Taku K, Melby MK, Nishi N, Omori T, Kurzer MS. Soy isoflavones for osteoporosis: an evidence-based approach. Maturitas (2011) 70(4):333-8. doi:10.1016/j.maturitas.2011.09.001

8. Taku K, Melby MK, Takebayashi J, Mizuno S, Ishimi Y, Omori T, et al. Effect of soy isoflavone extract supplements on bone mineral density in menopausal women: meta-analysis of randomized controlled trials. Asia Pac J Clin Nutr (2010) 19(1):33-42.

9. Wei P, Liu M, Chen Y, Chen DC. Systematic review of soy isoflavone supplements on osteoporosis in women. Asian Pac J Trop Med (2012) 5(3):243-8. doi:10.1016/S1995-7645(12)60033-9

10. Speroff L. Alternative therapies for postmenopausal women. Int J Fertil Womens Med (2005) 50(3):101-14.

11. van Die MD, Bone KM, Williams SG, Pirotta MV. Soy and soy isoflavones in prostate cancer: a systematic review and meta-analysis of randomised controlled trials. BJU Int (2014) 113(5b):e119-30. doi:10.1111/bju.12435

12. Hwang YW, Kim SY, Jee SH, Kim YN, Nam CM. Soy food consumption and risk of prostate cancer: a meta-analysis of observational studies. Nutr Cancer (2009) 61(5):598-606. doi:10.1080/01635580902825639

13. Yan L, Spitznagel EL. Soy consumption and prostate cancer risk in men: a revisit of a meta-analysis. Am J Clin Nutr (2009) 89(4):1155-63. doi:10.3945/ ajcn.2008.27029

14. Yan L, Spitznagel EL. Meta-analysis of soy food and risk of prostate cancer in men. Int J Cancer (2005) 117(4):667-9. doi:10.1002/ijc.21266

15. Myung SK, Ju W, Choi HJ, Kim SC. Korean Meta-Analysis (KORMA) Study Group. Soy intake and risk of endocrine-related gynaecological cancer: a meta-analysis. BJOG (2009) 116(13):1697-705. doi:10.1111/j.1471-0528.2009. 02322.x

16. Zhong X, Zhang C. Soy food intake and breast cancer risk: a meta-analysis. Wei Sheng Yan Jiu (2012) 41(4):670-6.

17. Dong JY, Qin LQ. Soy isoflavones consumption and risk of breast cancer incidence or recurrence: a meta-analysis of prospective studies. Breast Cancer Res Treat (2011) 125(2):315-23. doi:10.1007/s10549-010-1270-8

18. Enderlin CA, Coleman EA, Stewart CB, Hakkak R. Dietary soy intake and breast cancer risk. Oncol Nurs Forum (2009) 36(5):531-9. doi:10.1188/09.ONF.531539

19. Wu AH, Yu MC, Tseng CC, Pike MC. Epidemiology of soy exposures and breast cancer risk. Br J Cancer (2008) 98(1):9-14. doi:10.1038/sj.bjc.6604145

20. Qin LQ, Xu JY, Wang PY, Hoshi K. Soyfood intake in the prevention of breast cancer risk in women: a meta-analysis of observational epidemiological studies. J Nutr Sci Vitaminol (Tokyo) (2006) 52(6):428-36. doi:10.3177/jnsv.52.428
21. Trock BJ, Hilakivi-Clarke L, Clarke R. Meta-analysis of soy intake and breast cancer risk. J Natl Cancer Inst (2006) 98(7):459-71. doi:10.1093/jnci/djj102

22. Lethaby AE, Brown J, Marjoribanks J, Kronenberg F, Roberts H, Eden J. Phytoestrogens for vasomotor menopausal symptoms. Cochrane Database Syst Rev (2007) (4):CD001395. doi:10.1002/14651858.CD001395.pub3

23. Tempfer CB, Bentz EK, Leodolter S, Tscherne G, Reuss F, Cross HS, et al. Phytoestrogens in clinical practice: a review of the literature. Fertil Steril (2007) 87(6):1243-9. doi:10.1016/j.fertnstert.2007.01.120

24. Bolanos R, Del Castillo A, Francia J. Soy isoflavones versus placebo in the treatment of climacteric vasomotor symptoms: systematic review and metaanalysis. Menopause (2010) 17(3):660-6.

25. Daniel KT. The Whole Soy Story: The Dark Side of America's Favorite Health Food. Washington DC: New Trends Publishing, Inc. (2005).

26. Bhatia J, Greer F. American Academy of Pediatrics committee on nutrition. Use of soy protein-based formulas in infant feeding. Pediatrics (2008) 121(5):1062-8. doi:10.1542/peds.2008-0564

27. McCarver G, Bhatia J, Chambers C, Clarke R, Etzel R, Foster W, et al. NTPCERHR expert panel report on the developmental toxicity of soy infant formula. Birth Defects Res B Dev Reprod Toxicol (2011) 92(5):421-68. doi:10.1002/ bdrb. 20314

28. Barrett JR. The science of soy: what do we really know? Environ Health Perspect (2006) 114(6):A352-8. doi:10.1289/ehp.114-a352

29. Adgent MA, Daniels JL, Edwards LJ, Siega-Riz AM, Rogan WJ. Early-life soy exposure and gender-role play behavior in children. Environ Health Perspect (2011) 119(12):1811-6. doi:10.1289/ehp.1103579

30. Jing H, Gilchrist JM, Badger TM, Pivik RT. A longitudinal study of differences in electroencephalographic activity among breastfed, milk formula-fed, and soy formula-fed infants during the first year of life. Early Hum Dev (2010) 86(2):119-25. doi:10.1016/j.earlhumdev.2010.02.001

31. Li J, Dykman RA, Jing H, Gilchrist JM, Badger TM, Pivik RT. Cortical responses to speech sounds in 3- and 6-month-old infants fed breast milk, milk formula, or soy formula. Dev Neuropsychol (2010) 35(6):762-84. doi:10.1080/87565641. 2010.508547

32. Soucy NV, Parkinson HD, Sochaski MA, Borghoff SJ. Kinetics of genistein and its conjugated metabolites in pregnant Sprague-Dawley rats following single and repeated genistein administration. Toxicol Sci (2006) 90(1):230-40. doi:10.1093/toxsci/kfj077

33. Setchell KD, Zimmer-Nechemias L, Cai J, Heubi JE. Exposure of infants to phyto-oestrogens from soy-based infant formula. Lancet (1997) 350(9070):23-7. doi:10.1016/S0140-6736(96)09480-9

34. Setchell KD, Zimmer-Nechemias L, Cai J, Heubi JE. Isoflavone content of infant formulas and the metabolic fate of these phytoestrogens in early life. Am J Clin Nutr (1998) 68(6 Suppl):1453S-61S.

35. Westmark CJ, Westmark PR, Malter JS. Alzheimer's disease and Down syndrome rodent models exhibit audiogenic seizures. J Alzheimers Dis (2010) 20(4):1009-13. doi:10.3233/JAD-2010-100087

36. Westmark CJ, Westmark PR, O’Riordan KJ, Ray BC, Hervey CM, Salamat MS, et al. Reversal of fragile X phenotypes by manipulation of AbetaPP/Abeta levels in Fmrl mice. PLoS One (2011) 6(10):e26549. doi:10.1371/journal.pone. 0026549

37. Ricci MR, Ulman EA. Laboratory animal diets: a critical part of your research. Anim Lab News (2005) 4(6): 1 .

38. Westmark CJ, Westmark PR, Malter JS. Soy-based diet exacerbates seizures in mouse models of neurological disease. J Alzheimers Dis (2013) 33(3):797-805. doi:10.3233/JAD-2012-121426

39. Thigpen JE, Li LA, Richter CB, Lebetkin EH, Jameson CW. The mouse bioassay for the detection of estrogenic activity in rodent diets: II. Comparative estrogenic activity of purified, certified and standard open and closed formula rodent diets. Lab Anim Sci (1987) 37(5):602-5.

40. Santell RC, Kieu N, Helferich WG. Genistein inhibits growth of estrogenindependent human breast cancer cells in culture but not in athymic mice. J Nutr (2000) 130(7):1665-9.

41. Mohammadpour T, Hosseini M, Karami R, Sadeghnia HR, Ebrahimzadeh Bideskan AR, Enayatfard L. Estrogen-dependent effect of soy extract on pentylenetetrazole-induced seizures in rats. Zhong Xi Yi Jie He Xue Bao (2012) 10(12):1470-6. doi:10.3736/jcim20121221

42. Ebrahimzadeh Bideskan AR, Hosseini M, Mohammadpour T, Karami R, Khodamoradi M, Nemati Karimooy H, et al. Effects of soy extract on pentylenetetrazol-induced seizures in ovariectomized rats. Zhong Xi Yi Jie He Xиe Bao (2011) 9(6):611-8. doi:10.3736/jcim20110606 
43. Fattal-Valevski A, Bloch-Mimouni A, Kivity S, Heyman E, Brezner A, Strausberg R, et al. Epilepsy in children with infantile thiamine deficiency. Neurology (2009) 73(11):828-33. doi:10.1212/WNL.0b013e3181b121f5

44. Rodd C, Mushcab SA. Hypocalcemic seizures secondary to nutritional vitamin D deficiency in 3 infants fed soy formula. Clin Pediatr (Phila) (2005) 44(5):455-7. doi:10.1177/000992280504400512

45. Malloy $\mathrm{MH}$, Berendes $\mathrm{H}$. Does breast-feeding influence intelligence quotients at 9 and 10 years of age? Early Hum Dev (1998) 50(2):209-17. doi:10.1016/S0378-3732(97)00044-1

46. Strom BL, Schinnar R, Ziegler EE, Barnhart KT, Sammel MD, Macones GA, et al. Exposure to soy-based formula in infancy and endocrinological and reproductive outcomes in young adulthood. JAMA (2001) 286(7):807-14. doi:10.1001/jama.286.7.807

47. Zung A, Glaser T, Kerem Z, Zadik Z. Breast development in the first 2 years of life: an association with soy-based infant formulas. J Pediatr Gastroenterol Nutr (2008) 46(2):191-5. doi:10.1097/MPG.0b013e318159e6ae

48. Freni-Titulaer LW, Cordero JF, Haddock L, Lebrón G, Martínez R, Mills JL. Premature thelarche in Puerto Rico. A search for environmental factors. Am J Dis Child (1986) 140(12):1263-7. doi:10.1001/archpedi.1986. 02140260065028

49. Irvine CH, Shand N, Fitzpatrick MG, Alexander SL. Daily intake and urinary excretion of genistein and daidzein by infants fed soy- or dairy-based infant formulas. Am J Clin Nutr (1998) 68(6 Suppl):1462S-5S.

50. Setchell KD, Brown NM, Zhao X, Lindley SL, Heubi JE, King EC, et al. Soy isoflavone phase II metabolism differs between rodents and humans: implications for the effect on breast cancer risk. Am J Clin Nutr (2011) 94(5):1284-94. doi:10.3945/ajcn.111.019638

51. Howard TD, Ho SM, Zhang L, Chen J, Cui W, Slager R, et al. Epigenetic changes with dietary soy in cynomolgus monkeys. PLoS One (2011) 6(10):e26791. doi:10.1371/journal.pone.0026791

52. Jin $\mathrm{Y}, \mathrm{Wu} \mathrm{H}$, Cohen EM, Wei J, Jin H, Prentice H, et al. Genistein and daidzein induce neurotoxicity at high concentrations in primary rat neuronal cultures. J Biomed Sci (2007) 14(2):275-84. doi:10.1007/s11373-006-9142-2

53. Brown NM, Setchell KD. Animal models impacted by phytoestrogens in commercial chow: implications for pathways influenced by hormones. Lab Invest (2001) 81(5):735-47. doi:10.1038/labinvest.3780282

54. Volkmar FR, Nelson DS. Seizure disorders in autism. J Am Acad Child Adolesc Psychiatry (1990) 29(1):127-9. doi:10.1097/00004583-199001000-00020

55. Giovanardi Rossi P, Posar A, Parmeggiani A. Epilepsy in adolescents and young adults with autistic disorder. Brain Dev (2000) 22(2):102-6. doi:10. 1016/S0387-7604(99)00124-2

56. Westmark CJ. Soy infant formula and seizures in children with autism: a retrospective study. PLoS One (2014) 9(3):e80488. doi:10.1371/journal.pone. 0080488

57. Westmark CJ. Soy infant formula may be associated with autistic behaviors. Autism Open Access (2013) 3(3):e1000120. doi:10.1111/j.1469-8749.2008. 03161.x

58. Hagerman RJ, Hagerman PJ. Physical and Behavioral Phenotype. Baltimore: John Hopkins University Press (2002).

59. Verkerk AJ, Pieretti M, Sutcliffe JS, Fu YH, Kuhl DP, Pizzuti A, et al. Identification of a gene (FMR-1) containing a CGG repeat coincident with a breakpoint cluster region exhibiting length variation in fragile X syndrome. Cell (1991) 65(5):905-14. doi:10.1016/0092-8674(91)90397-H

60. Oberle I, Rousseau F, Heitz D, Kretz C, Devys D, Hanauer A, et al. Instability of a 550-base pair DNA segment and abnormal methylation in fragile X syndrome. Science (1991) 252(5010):1097-102. doi:10.1126/science.252.5009. 1097

61. Chonchaiya W, Au J, Schneider A, Hessl D, Harris SW, Laird M, et al. Increased prevalence of seizures in boys who were probands with the FMR1 premutation and co-morbid autism spectrum disorder. Hum Genet (2012) 131(4):581-9. doi:10.1007/s00439-011-1106-6

62. Autism and Developmental Disabilities Monitoring Network Surveillance Year 2008 Principal Investigators and Centers for Disease Control and Prevention. Prevalence of autism spectrum disorders - autism and developmental disabilities monitoring network, 14 sites, United States, 2008. MMWR Surveill Summ (2012) 61(3):1-19.

63. Newschaffer CJ, Croen LA, Daniels J, Giarelli E, Grether JK, Levy SE, et al. The epidemiology of autism spectrum disorders. Annu Rev Public Health (2007) 28:235-58. doi:10.1146/annurev.publhealth.28.021406.144007
64. Hessl D, Dyer-Friedman J, Glaser B, Wisbeck J, Barajas RG, Taylor A, et al. The influence of environmental and genetic factors on behavior problems and autistic symptoms in boys and girls with fragile X syndrome. Pediatrics (2001) 108(5):E88. doi:10.1542/peds.108.5.e88

65. Spencer CM, Alekseyenko O, Hamilton SM, Thomas AM, Serysheva E, Yuva-Paylor LA, et al. Modifying behavioral phenotypes in Fmr1KO mice: genetic background differences reveal autistic-like responses. Autism Res (2011) 4(1):40-56. doi:10.1002/aur.168

66. Clifford S, Dissanayake C, Bui QM, Huggins R, Taylor AK, Loesch DZ. Autism spectrum phenotype in males and females with fragile $\mathrm{X}$ full mutation and premutation. J Autism Dev Disord (2007) 37(4):738-47. doi:10.1007/s10803006-0205-z

67. Amiet C, Gourfinkel-An I, Bouzamondo A, Tordjman S, Baulac M, Lechat $\mathrm{P}$, et al. Epilepsy in autism is associated with intellectual disability and gender: evidence from a meta-analysis. Biol Psychiatry (2008) 64(7):577-82. doi:10.1016/j.biopsych.2008.04.030

68. Hartley-McAndrew M, Weinstock A. Autism spectrum disorder: correlation between aberrant behaviors, EEG abnormalities and seizures. Neurol Int (2010) 2(1):e10. doi:10.4081/ni.2010.e10

69. Wheless JW, Simos PG, Butler IJ. Language dysfunction in epileptic conditions. Semin Pediatr Neurol (2002) 9(3):218-28. doi:10.1053/spen.2002.35504

70. van Eeghen AM, Pulsifer MB, Merker VL, Neumeyer AM, van Eeghen EE, Thibert RL, et al. Understanding relationships between autism, intelligence, and epilepsy: a cross-disorder approach. Dev Med Child Neurol (2013) 55(2):146-53. doi:10.1111/dmcn.12044

71. Hagerman RJ. Epilepsy drives autism in neurodevelopmental disorders. Dev Med Child Neurol (2013) 55(2):101-2. doi:10.1111/dmcn.12071

72. Polanczyk G, de Lima MS, Horta BL, Biederman J, Rohde LA. The worldwide prevalence of ADHD: a systematic review and metaregression analysis. Am J Psychiatry (2007) 164(6):942-8. doi:10.1176/appi.ajp.164.6.942

73. Akinbami LJ, Liu X, Pastor PN, Reuben CA. Attention deficit hyperactivity disorder among children aged 5-17 years in the United States, 1998-2009. NCHS Data Brief (2011) (70):1-8.

74. Matson JL, Rieske RD, Williams LW. The relationship between autism spectrum disorders and attention-deficit/hyperactivity disorder: an overview. Res Dev Disabil (2013) 34(9):2475-84. doi:10.1016/j.ridd.2013.05.021

75. Dunn DW, Austin JK, Harezlak J, Ambrosius WT. ADHD and epilepsy in childhood. Dev Med Child Neurol (2003) 45(1):50-4. doi:10.1111/j.1469-8749.2003. tb00859.x

76. Parisi P, Moavero R, Verrotti A, Curatolo P. Attention deficit hyperactivity disorder in children with epilepsy. Brain Dev (2010) 32(1):10-6. doi:10.1016/j. braindev.2009.03.005

77. Cohen R, Senecky Y, Shuper A, Inbar D, Chodick G, Shalev V, et al. Prevalence of epilepsy and attention-deficit hyperactivity (ADHD) disorder: a population-based study. J Child Neurol (2012) 28(1):120-3. doi:10.1177/ 0883073812440327

78. Hesdorffer DC, Ludvigsson P, Olafsson E, Gudmundsson G, Kjartansson O, Hauser WA. ADHD as a risk factor for incident unprovoked seizures and epilepsy in children. Arch Gen Psychiatry (2004) 61(7):731-6. doi:10.1001/ archpsyc.61.7.731

79. Hermann B, Jones J, Dabbs K, Allen CA, Sheth R, Fine J, et al. The frequency, complications and aetiology of ADHD in new onset paediatric epilepsy. Brain (2007) 130(Pt 12):3135-48. doi:10.1093/brain/awm227

80. Iossifov I, Ronemus M, Levy D, Wang Z, Hakker I, Rosenbaum J, et al. De novo gene disruptions in children on the autistic spectrum. Neuron (2012) 74(2):285-99. doi:10.1016/j.neuron.2012.04.009

81. Chapman RW, Laidlow JM, Colin-Jones D, Eade OE, Smith CL. Increased prevalence of epilepsy in coeliac disease. Br Med J (1978) 2(6132):250-1. doi:10.1136/bmj.2.6132.250

82. Schneider JS, Decamp E, Clark K, Bouquio C, Syversen T, Guilarte TR. Effects of chronic manganese exposure on working memory in non-human primates. Brain Res (2009) 1258:86-95. doi:10.1016/j.brainres.2008.12.035

83. Schneider JS, Decamp E, Koser AJ, Fritz S, Gonczi H, Syversen T, et al. Effects of chronic manganese exposure on cognitive and motor functioning in nonhuman primates. Brain Res (2006) 1118(1):222-31. doi:10.1016/j.brainres. 2006.08.054

84. Crinella FM. Does soy-based infant formula cause ADHD? Update and public policy considerations. Expert Rev Neurother (2012) 12(4):395-407. doi:10.1586/ern.12.2 
85. Berger-Achituv S, Shohat T, Romano-Zelekha O, Ophir E, Rachmani S, Malovizky D, et al. Widespread use of soy-based formula without clinical indications. J Pediatr Gastroenterol Nutr (2005) 41(5):660-6. doi:10.1097/01.mpg. 0000181855.77488.bf

86. Cohen R, Senecky Y, Shuper A, Inbar D, Chodick G, Shalev V, et al. Prevalence of epilepsy and attention-deficit hyperactivity (ADHD) disorder: a population-based study. J Child Neurol (2013) 28(1):120-3. doi:10.1177/ 0883073812440327

87. Bear MF, Huber KM, Warren ST. The mGluR theory of fragile X mental retardation. Trends Neurosci (2004) 27(7):370-7. doi:10.1016/j.tins.2004.04. 009

88. Dolen G, Osterweil E, Rao BS, Smith GB, Auerbach BD, Chattarji S, et al. Correction of fragile X syndrome in mice. Neuron (2007) 56(6):955-62. doi:10.1016/j.neuron.2007.12.001

89. Yan QJ, Rammal M, Tranfaglia M, Bauchwitz RP. Suppression of two major fragile X syndrome mouse model phenotypes by the mGluR5 antagonist MPEP. Neuropharmacology (2005) 49(7):1053-66. doi:10.1016/j.neuropharm. 2005.06.004

90. de Vrij FM, Levenga J, van der Linde HC, Koekkoek SK, De Zeeuw CI, Nelson DL, et al. Rescue of behavioral phenotype and neuronal protrusion morphology in Fmrl KO mice. Neurobiol Dis (2008) 31(1):127-32. doi:10.1016/j.nbd.2008.04.002

91. Michalon A, Sidorov M, Ballard TM, Ozmen L, Spooren W, Wettstein JG, et al. Chronic pharmacological mGlu5 inhibition corrects fragile $\mathrm{X}$ in adult mice. Neuron (2012) 74(1):49-56. doi:10.1016/j.neuron.2012.03.009

92. Woolley CS. Acute effects of estrogen on neuronal physiology. Annu Rev Pharmacol Toxicol (2007) 47:657-80. doi:10.1146/annurev.pharmtox.47.120505. 105219

93. Hojo Y, Hattori TA, Enami T, Furukawa A, Suzuki K, Ishii HT, et al. Adult male rat hippocampus synthesizes estradiol from pregnenolone by cytochromes P45017alpha and P450 aromatase localized in neurons. Proc Natl Acad Sci U S A (2004) 101(3):865-70. doi:10.1073/pnas.2630225100

94. Mermelstein PG, Micevych PE. Nervous system physiology regulated by membrane estrogen receptors. Rev Neurosci (2008) 19(6):413-24.

95. Milner TA, Ayoola K, Drake CT, Herrick SP, Tabori NE, McEwen BS, et al. Ultrastructural localization of estrogen receptor beta immunoreactivity in the rat hippocampal formation. J Comp Neurol (2005) 491(2):81-95. doi:10.1002/ cne.20724

96. Cederroth CR, Zimmermann C, Nef S. Soy, phytoestrogens and their impact on reproductive health. Mol Cell Endocrinol (2012) 355(2):192-200. doi:10. 1016/j.mce.2011.05.049

97. Loesch DZ, Huggins RM, Hoang NH. Growth in stature in fragile X families: a mixed longitudinal study. Am J Med Genet (1995) 58(3):249-56. doi:10.1002/ajmg.1320580311

98. Purcell AL, Carew TJ. Modulation of excitability in Aplysia tail sensory neurons by tyrosine kinases. J Neurophysiol (2001) 85(6):2398-411.

99. Bonsi P, Cuomo D, De Persis C, Centonze D, Bernardi G, Calabresi P, et al. Modulatory action of metabotropic glutamate receptor (mGluR) 5 on mGluR1 function in striatal cholinergic interneurons. Neuropharmacology (2005) 49(Suppl 1):104-13. doi:10.1016/j.neuropharm.2005.05.012

100. Liu L, Yang T, Simon SA. The protein tyrosine kinase inhibitor, genistein, decreases excitability of nociceptive neurons. Pain (2004) 112(1-2):131-41. doi:10.1016/j.pain.2004.08.005

101. Dunne EL, Moss SJ, Smart TG. Inhibition of GABAA receptor function by tyrosine kinase inhibitors and their inactive analogues. Mol Cell Neurosci (1998) 12(4-5):300-10. doi:10.1006/mcne.1998.0717

102. Boulware MI, Mermelstein PG. Membrane estrogen receptors activate metabotropic glutamate receptors to influence nervous system physiology. Steroids (2009) 74(7):608-13. doi:10.1016/j.steroids.2008.11.013

103. Grove-Strawser D, Boulware MI, Mermelstein PG. Membrane estrogen receptors activate the metabotropic glutamate receptors mGluR5 and mGluR3 to bidirectionally regulate CREB phosphorylation in female rat striatal neurons. Neuroscience (2010) 170(4):1045-55. doi:10.1016/j.neuroscience.2010. 08.012

104. Meitzen J, Mermelstein PG. Estrogen receptors stimulate brain region specific metabotropic glutamate receptors to rapidly initiate signal transduction pathways. J Chem Neuroanat (2011) 42(4):236-41. doi:10.1016/j.jchemneu.2011. 02.002

105. Mermelstein PG. Membrane-localised oestrogen receptor alpha and beta influence neuronal activity through activation of metabotropic glutamate receptors. J Neuroendocrinol (2009) 21(4):257-62. doi:10.1111/j.1365-2826. 2009.01838.x

106. Donovan SM, Andres A, Mathai RA, Kuhlenschmidt TB, Kuhlenschmidt MS Soy formula and isoflavones and the developing intestine. Nutr Rev (2009) 67(Suppl 2):S192-200. doi:10.1111/j.1753-4887.2009.00240.x

107. Hoey L, Rowland IR, Lloyd AS, Clarke DB, Wiseman H. Influence of soyabased infant formula consumption on isoflavone and gut microflora metabolite concentrations in urine and on faecal microflora composition and metabolic activity in infants and children. Br J Nutr (2004) 91(4):607-16. doi:10.1079/ BJN20031083

108. Piacentini G, Peroni D, Bessi E, Morelli L. Molecular characterization of intestinal microbiota in infants fed with soymilk. J Pediatr Gastroenterol Nutr (2010) 51(1):71-6. doi:10.1097/MPG.0b013e3181dc8b02

109. Setchell KD, Clerici C. Equol: history, chemistry, and formation. J Nutr (2010) 140(7):1355S-62S. doi:10.3945/jn.109.119776

110. Jackson RL, Greiwe JS, Schwen RJ. Emerging evidence of the health benefits of S-equol, an estrogen receptor beta agonist. Nutr Rev (2011) 69(8):432-48. doi:10.1111/j.1753-4887.2011.00400.x

111. Bosviel R, Durif J, Dechelotte P, Bignon YJ, Bernard-Gallon D. Epigenetic modulation of BRCA1 and BRCA2 gene expression by equol in breast cancer cell lines. Br J Nutr (2012) 108(7):1187-93. doi:10.1017/S000711451100657X

112. Spisák S, Solymosi N, Ittzés P, Bodor A, Kondor D, Vattay G, et al. Complete genes may pass from food to human blood. PLoS One (2013) 8(7):e69805. doi:10.1371/journal.pone.0069805

113. Smith JM. Genetic Roulette: The Documented Health Risks of Genetically Engineered Foods. White River Junction, VT: Chelsea Green (2007).

114. Samsel A, Seneff S. Glyphosate's suppression of cytochrome P450 enzymes and amino acid biosynthesis by the gut microbiome: pathways to modern diseases. Entropy (2013) 15:1-48. doi:10.3390/e15041416

115. Ravizza T, Kostoula C, Vezzani A. Immunity activation in brain cells in epilepsy: mechanistic insights and pathological consequences. Neuropediatrics (2013) 44(6):330-5. doi:10.1055/s-0033-1358601

116. Marchi N, Granata T, Janigro D. Inflammatory pathways of seizure disorders. Trends Neurosci (2014) 37(2):55-65. doi:10.1016/j.tins.2013.11.002

117. Curran EM, Judy BM, Newton LG, Lubahn DB, Rottinghaus GE, Macdonald RS, et al. Dietary soy phytoestrogens and ERalpha signalling modulate interferon gamma production in response to bacterial infection. Clin Exp Immunol (2004) 135(2):219-25. doi:10.1111/j.1365-2249.2003.02368.x

118. Zhang R, Li Y, Wang W. Enhancement of immune function in mice fed high doses of soy daidzein. Nutr Cancer (1997) 29(1):24-8. doi:10.1080/ 01635589709514597

119. Chighizola C, Meroni PL. The role of environmental estrogens and autoimmunity. Autoimmun Rev (2012) 11(6-7):A493-501. doi:10.1016/j.autrev.2011.11. 027

120. Bargerstock E, Puvenna V, Iffland P, Falcone T, Hossain M, Vetter S, et al. Is peripheral immunity regulated by blood-brain barrier permeability changes? PLoS One (2014) 9(7):e101477. doi:10.1371/journal.pone.0101477

121. Choy M, Dube CM, Ehrengruber M, Baram TZ. Inflammatory processes, febrile seizures, and subsequent epileptogenesis. Epilepsy Curr (2014) 14(1 Suppl):15-22. doi:10.5698/1535-7511-14.s2.15

122. Polack FP, Khan N, Maisels MJ. Changing partners: the dance of infant formula changes. Clin Pediatr (Phila) (1999) 38(12):703-8. doi:10.1177/ 000992289903801202

Conflict of Interest Statement: The author declares that the research was conducted in the absence of any commercial or financial relationships that could be construed as a potential conflict of interest.

Received: 15 April 2014; accepted: 21 August 2014; published online: 03 September 2014.

Citation: Westmark CJ (2014) A hypothesis regarding the molecular mechanism underlying dietary soy-induced effects on seizure propensity. Front. Neurol. 5:169. doi: 10.3389/fneur.2014.00169

This article was submitted to Epilepsy, a section of the journal Frontiers in Neurology. Copyright (c) 2014 Westmark. This is an open-access article distributed under the terms of the Creative Commons Attribution License (CC BY). The use, distribution or reproduction in other forums is permitted, provided the original author(s) or licensor are credited and that the original publication in this journal is cited, in accordance with accepted academic practice. No use, distribution or reproduction is permitted which does not comply with these terms. 